\title{
Where do we go from here? A research agenda for entrepreneurial cognitions
}

\author{
Malin Brännback and Alan L. Carsrud
}

\section{Focus of this volume}

In this edited book of eleven chapters, we examine a variety of approaches that may be useful in advancing our understanding of the cognitions that drive entrepreneurial activity. Although we pay special attention to entrepreneurial intentions because it is perhaps the widely researched cognitions, our focus is far broader. In our previous books on this general topic (Carsrud \& Brännback, 2009; Brännback \& Carsrud, 2017) we examined a variety of key areas in the psychology of the entrepreneur and subsequently how that research changed over the course of some nine years. We have also suggested that serious research methods issues limit our understanding of entrepreneurial processes (Carsrud \& Brännback, 2014). In this volume, we move beyond what has been done to take a more forward-looking approach. We do this by examining areas we feel still have been under-researched, ignored, or are often not thought of as having an impact on the thinking and cognitions of entrepreneurs. We are most appreciative of the publisher, Edward Edgar, for their willingness to allow us to take a more forwardlooking approach.

\section{Rationale behind the volume}

We were partially driven to this tactic after realizing that most of our fellow researchers and educators in entrepreneurship think they are doing the right thing in the right way. Yet when one asks real entrepreneurs and business owners how they perceive research in the field, few think the published research addresses issues important to them. This is not just cognitive research but most of what we publish in our field. Perhaps we need to not only better understand what our "customer" wants to know, but also other methods of trying to research the cognitive aspects of entrepreneurs. In fact, we are seeing this across all disciplines. Increasing university research is not very highly considered nor is it accessible outside universities. This seems to have become a harsh reality on a global level. The monopoly position of universities as institutions where new knowledge is created is increasingly no longer there. This is especially true of academic schools of business administration, not just the STEM subjects. 


\section{Role of relevance}

We need to take a broader view of topics and approaches if we are to continue to be relevant as business academics. We cannot continue to borrow theories from other disciplines that are years out of date in those home disciplines like psychology, sociology, and economics. For example, we cannot keep doing the same old intentions studies, based on the Theory of Planned Behavior, with a different population and using the same old linear models (even structure equation models are based on linearity). Most of what is submitted to entrepreneurship journals is fine tuning what we already know. In general, very few new questions are being raised and we are not really providing any great answers. If we look at entrepreneurship research, which should be at its core applied work, we find a lot of the research is not really helping entrepreneurs with their problems. As hard as it may sound, take an unbiased look at articles being published in high impact journals in the field of entrepreneurship. Do these studies really create new and potentially useful knowledge? If you challenge the status quo with a new theory or methodology you are not likely to survive the peer review process, at least with reviewers who may have a vested interest in a given theory or approach.

We have argued, mostly unsuccessful to date, that the field of entrepreneurship like psychology, sociology, anthropology, and strategic management are still seeking the illusive unified definition of the field and, consequently, an underlying theory (or more likely multiple theories) to support a given discipline. Often this search has caused us to lose sight of relevance to the subject of our research, the entrepreneur, and their venture. Entrepreneurship lacks not only a unified theory, but also no real consensus on what should be the topics. Frankly, while it is exciting to have a broad range of topics, we still have disagreements on what are the characteristics of an entrepreneur and an entrepreneurial firm. If we are to make advances, we need to start adopting or developing theories that can give it legitimacy within the general study of social phenomena and relevance to those who practice it.

\section{Volume overview}

Thus we have asked a number of our colleagues to weigh in on the future direction of the cognitive study of entrepreneurs. They were asked not to review what has been done, but to propose new directions that may be more fruitful and relevant. As a result, we have eleven chapters that cover more traditional areas like intentions and motivations, to new research tools and models, the role culture plays in changing cognitions, and how language impacts the entrepreneur. A brief discussion of the contents of each subsequent chapter to this introductory one follows.

\section{Chapter 2}

We begin this edited volume with a chapter that uses a novel way to look at the area of entrepreneurial intentions research that employs a methodology that allows 
a look at the true complexity of intentions. For over three decades, hundreds of studies have been conducted in a wide range of contexts on entrepreneurial intent and subsequent behavior. As a result, numerous researchers have addressed a wide range of concepts and themes. However, due to the number of articles, chapters, and books, it has become more and more difficult to link all those different concepts. The aim of this chapter, therefore, is to provide a map of the structure topics around entrepreneurial intent and behavior. This allows the reader to develop an appropriate "sightseeing tour" of this entrepreneurial theme that has become increasingly relevant to many researchers and policy makers. You can think of this as a map of the field, the sub-concepts, and the key research players.

\section{Chapter 3}

This chapter builds upon the "on again-off again" attempt to find a unique entrepreneurial personality. The authors show how the examination of entrepreneurial personality was largely abandoned when a systematic attempt to study motivation in entrepreneurs, using then "state-of-the-art" theories of achievement motivation, failed to find a "unique model" for entrepreneurs. They also demonstrate that the study of the entrepreneur as a whole individual has not usually been the unit of analysis. Too often studies of "personality" at best have been studies of observable behaviors, which some confuse for personality traits. One of the dangers confronting anyone who would borrow theory and method from another discipline is that the borrowing may be incomplete in some critical way. This problem can be exacerbated if the borrowing is done by scholars who, though well-meaning and conscientious, were not originally trained in the parent discipline. The authors then discuss the most recent approach to personality research in psychology, which uses the Big Five (or Six) Factors. One of the objectives of modern personality measurement has been to identify just a few latent dimensions on which people can be characterized. The "Big Five" are Conscientiousness, Agreeableness, Neuroticism, Openness to experience, and Extraversion arranged in one mnemonic order: CANOE.

\section{Chapter 4}

In this chapter, our colleagues acknowledge that entrepreneurial intention models are well established in the entrepreneurship literature. However, they note the persistent problem of the low rate of transformation of intentions into action. They note that we still know little about the factors that contribute to this transformation. This chapter focuses on the role of culture in the entrepreneurial process. By identifying two components of culture (values and practices) the authors argue that the mode of influence for each is different. That is, cultural values shape personal motivations, attitudes and intentions, while cultural practices affect the actual start-up behaviors. More importantly they note that the interaction with the economic conditions must also be considered. They conclude by providing an integrative model for the culture's mode of influence on the entrepreneurial process. 


\section{Chapter 5}

This chapter challenges the vast majority of existing work on intentions by arguing we need to improve our understanding of the role of intentions in start-up teams of entrepreneurs and family firm succession by moving beyond the traditional view of individual intentions in entrepreneurial settings and toward understanding collective intentions. For example, in a start-up there is often a small group whose individual intentions for entering the firm and setting its strategic direction must blend to some form of consensus such as marketing and growth strategy. In addition, in a family firm the intentions toward succession are as much collective as individual. If we seek we-intent to increase the possibility of successful succession, then a focus on "we" intentions allows for a better understanding of the potentially conflicting intentions of key individuals. This chapter argues that the conceptualization of collective intent, such as "we-intentions", offers a better understanding of group processes from a social cognition perspective, especially those of succession. However, collective intentions (and their measurement) are still less understood.

\section{Chapter 6}

As in the previous chapter, this one looks at the wide application of the Theory of Planned Behavior (TPB) in entrepreneurship research to predict intention to start a new venture, entrepreneurial intention. It shows that very limited research has examined the relationship between entrepreneurial intentions and the subsequent enactment of those intentions. Even though TPB is considered sufficient and enjoys impressive meta-analytical support, research on the association between intentions and behavior is wanting. What this chapter proposes is the role of Implementation Intentions. This conceptualization holds potential to shed light upon the intentionbehavior relationship, conceptually and empirically. Thus, the chapter draws attention to implementation intentions for future research to enhance explanation and prediction of when, where, and how some, but not others, enact their entrepreneurial intentions by launching new ventures.

\section{Chapter 7}

The focus of this chapter returns to the role of motivation. As the authors note, research in entrepreneurial motivation often suffers from narrow theoretical articulation and a lack of integration of the psychological, cognitive, and affective aspects. Over the past decade there has been renewed interest in affective components of entrepreneurial motivation, including passion, compassion, and founder's self- and social identities and the role they play in opportunity recognition and venture formation. This chapter provides a new understanding of entrepreneurial motivation based on an integrative review of cognitive and affective motivational constructs and opportunity recognition. The authors conclude with a process model and provide directions for future research. 


\section{Chapter 8}

In this chapter the focus moves to shifting methodologies for studying entrepreneurial cognitions. The authors acknowledge that understanding entrepreneurial intention has been - and still is - a highly relevant research problem. Traditional approaches in this domain utilize theories rooted in the Theory of Reasoned Action and Theory of Planned Behavior, and rely on tools offered by regression analysis-based approaches. In contrast to this widely used combination, the authors demonstrate why new theoretically justified constructs and a more causal explanation-oriented data analysis approach can complement and improve existing literature. Where previous research tests the individual impact of independent variables on one or two dependent variables, this chapter introduces a method that analyzes the combined effects of variables on an outcome through Fuzzy-set Qualitative Comparative Analysis (FsQCA). FsQCA can be used as a basis of performing classification tasks to identify individuals with entrepreneurial intention potential. With this approach we see that there is more than one solution to a specific outcome. This, in turn, may partially explain why many previous entrepreneurial intention studies have provided mixed results across different samples. The introduced approach also addresses one of the most important methodological shortcomings of FsQCA, namely parameter selection in deriving important sufficient rules. The authors demonstrate this contribution using a dataset collected from eight countries.

\section{Chapter 9}

This chapter looks at the contextual variable of organizational culture as a resource that impacts organizational growth and/or success by guiding both structure and function of a venture serving as a source of competitive advantage. The authors note that culture is sometimes directly studied in the entrepreneurship research, but is most likely considered as the creation of an "entrepreneurial culture" in a venture or an entrepreneurial climate for a geographic region. What needs an answer is the question of how the organizational culture of a new venture is created. Given that organizational culture is based on a system of shared values and beliefs, the authors propose an articulated pathway of the cognitive relationship between the values and beliefs of the founder(s) and the eventual culture of the founded organization. In reviewing the literature, they show how the perceptions, expectations, and values of the founder(s) influence the kind of business and its growth patterns over time. However, what is still needed is research that examines how aspects of the entrepreneur's identity are manifested inside the new organization, the processes by which this occurs, and the structure and organizational practices it may lead to for all members. The authors go beyond our current understanding of the pathway between individual identity, entrepreneurial identity, and organizational identity in order to explore organizational culture predicated as a key component of that organizational identity. They finally propose a preliminary conceptual framework and propositions regarding the pathway for culture creation in new ventures and conclude with suggestions for future research as well as the impact on entrepreneurship education and practice. 


\section{Chapter 10}

Following the previous chapter on entrepreneurial education, this chapter examines the extant literature, which recognizes the important role of learning in the entrepreneurial process. Learning has clearly been a cognitive process that has largely been ignored by entrepreneurship researchers. However, few studies have explored how learning takes place in a mutual interaction with new venture ideas (NVIs). This paper aims to build theoretical understanding about the interplays between the developments of NVIs and how entrepreneurs learn. Using an inductive multiple-case study with six entrepreneurs in Norway, the authors find that NVIs trigger the learning of entrepreneurs at several occasions and, by transforming experiences into knowledge, thus entrepreneurs further develop the new venture ideas. The chapter focuses on the mechanisms of this co-development process.

\section{Chapter 11}

This chapter builds on entrepreneurship as narratives and discourse reflecting the thoughts and actions of the entrepreneur. Existing work shows the importance of the entrepreneurial language because the words individuals speak are proxies of their thoughts that guide their behaviors. Words are how entrepreneurs communicate their thoughts and desires to others. By studying language, researchers can gain insights into the entrepreneur's world, and by looking at language, one gains an understanding of the cognitive factors that drive entrepreneurial intention and action during the complex process of new venture creation. Recent work in entrepreneurship has begun to lever linguistic lenses to understand how language influences entrepreneurial behavior. Linguistic theories and analysis build upon and extend the discursive and narrative analysis. The authors note that linguistics differs from narratives and discourse analysis, and is the scientific study of language, focusing on the actual structure of language, patterns, word grouping, among other areas, to demonstrate how the language an actor uses can impact many decisions, including economic decisions, and is an important influential intuitional force.

\section{References}

Brännback, M. \& Carsrud, A. L. (eds) (2017). Revisiting the Entrepreneurial Mind: Inside the Black Box. Springer: New York, NY.

Carsrud, A. L. \& Brännback, M. (eds) (2009). Understanding the Entrepreneurial Mind: Opening the Black Box. Springer: New York, NY.

Carsrud, A. L. \& Brännback, M. (eds) (2014). Handbook of Research Methods and Applications in Entrepreneurship and Small Business. Edward Edgar: Cheltenham, UK. 